\section{Bilateral chylothorax complicating massive osteolysis (Gorham's syndrome)}

Pratheep Riantawan, Sudarat Tansupasawasdikul, Ponglada Subhannachart

\begin{abstract}
Chylothorax may rarely occur in osteolysis. A fatal case of bilateral chylothorax complicating massive osteolysis is described and the pathogenesis and management are discussed.
\end{abstract}

(Thorax 1996;51:1277-1278)

Keywords: chylothorax, massive osteolysis, Gorham's syndrome.

A 27 year old man was admitted with a one month history of progressive shortness of breath. Past medical history disclosed repeated clavicular fractures after minor injuries. Physical examination showed him to be undernourished, apyrexial, but tachypnoeic (respiratory rate $28 / \mathrm{min}$ ). There were signs of bilateral pleural effusions. The chest radiograph showed bilateral massive pleural effusions, absence of both clavicles, and demineralisation of the left first rib and medial part of the left scapula. The serum albumin level was low at $28 \mathrm{~g} / 1$ but haematological and other biochemical findings were normal.

Bilateral thoracentesis yielded white milky fluid with a laboratory analysis consistent with chyle. Cytological examination and cultures showed no malignant cells or microorganisms. His respiratory compromise necessitated repeated aspirations and, subsequently, bilateral intercostal tube drainage. Gastrointestinal rest and total parenteral hyperalimentation were promptly instituted. Lymphangiography showed normal lymph channels in the inguinal and lumbar areas, but areas of minimal contrast leakage were noted in the upper and lower part of the left thoracic cavity; however, the thoracic duct was not visualised on the 24 and 48 hour films. Subsequent chest radiographs showed progressive resorption of the left first to third ribs, left transverse processes of the first to third thoracic vertebrae, part of the body of the seventh cervical vertebra, spinous process of the left scapula, and the right first and second ribs (figure).

Despite maximal nutritional support his condition deteriorated. Chest tube drainage persisted at a rate of approximately $1500 \mathrm{ml} /$ day. By the third week a diagnosis of massive osteolysis was considered and open thoracotomy with a view to thoracic duct ligation was planned. However, the patient rapidly de-

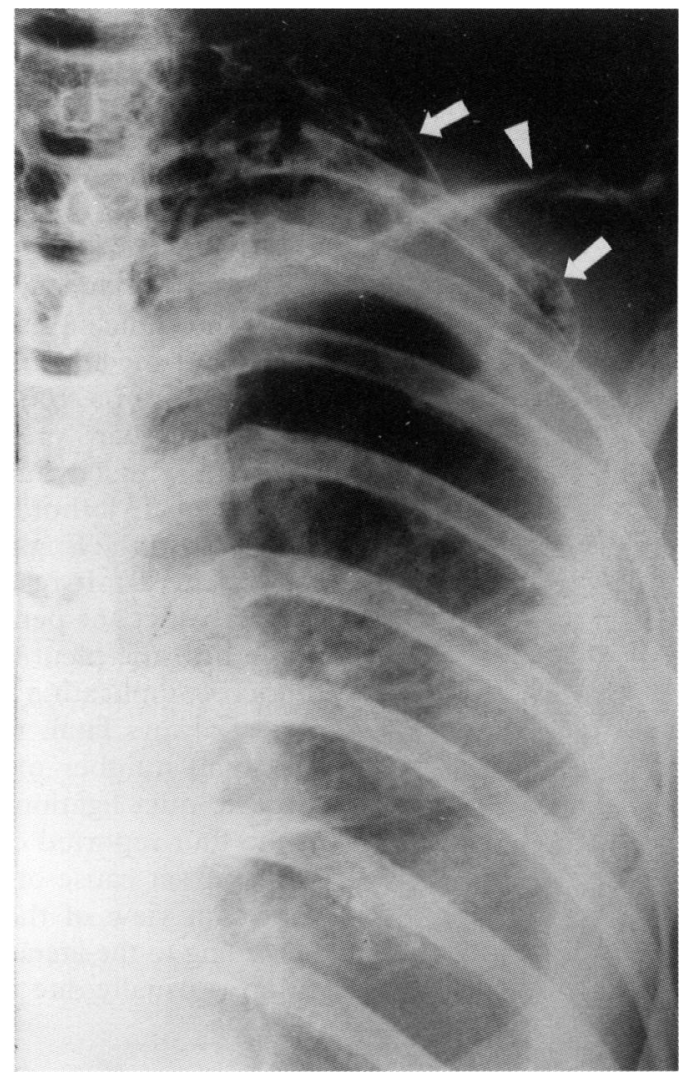

Figure 1 Chest radiograph showing resorption of the left first and second ribs (arrows), thinning of the spinous process of the left scapula (arrowhead), and left pleural effusion. The left clavicle is absent.

teriorated and died the following day. Necroscopic examination of the affected ribs showed enlargement of the marrow spaces which were completely replaced by numerous lymphatic vessels.

\section{Discussion}

Massive osteolysis (Gorham's syndrome) is a rare disease of unknown aetiology characterised by progressive resorption of bones. The recognition of this syndrome stemmed from the case reports and a review of histological findings by Gorham and Stout in the 1950s. ${ }^{12}$

There are no unifying histological features; however, the osteolysis is typically associated with a proliferation of thin walled, endothelial lined capillary or sinusoidal vascular channels, usually blood vessels, but lymphatic vessels as in our case have also been described. ${ }^{34}$ The lesions are histologically benign and there is minimal, if any, osteoclastic activity.

The haemangiomas or lymphangiomas may extend and destroy adjacent bones. The mechanism of bone resorption is currently unknown. There is a propensity for involvement of the maxilla, shoulder girdle, ribs, spine and pelvis. ${ }^{5}$ Dull aching, weakness in an affected limb, and skeletal deformities are prominent features. Spontaneous arrest has been noted in some cases. ${ }^{12}$ The ultimate extent of the disorder cannot be predicted from the initial lesion and widespread involvement of the skeleton, particularly of the spine and thorax, may result in neurological and pulmonary sequelae. 
Osteolysis may result from systemic diseases such as rheumatoid arthritis and hyperparathyroidism. Hereditary osteolysis may show dominant or, rarely, recessive transmission. It presents in childhood and primarily involves the hands and feet. ${ }^{6}$ Essential osteolysis is characterised by resorption of carpal and/or tarsal bones with progressive renal failure ${ }^{6}$ The clinical presentation and histological findings of the affected bones distinguish Gorham's syndrome from these clinical entities.

Of particular interest is the unusual association with chylothorax. There have been 25 cases of chylothorax complicating Gorham's syndrome in the English literature, 10 of which were bilateral. ${ }^{7}$ It results from invasion of the thoracic duct ${ }^{7}$ or penetration of vascular dysplasia into the pleural cavity. ${ }^{8}$ Bilateral chylothorax complicating Gorham's syndrome is almost always fatal. Based on the evidence of the small number of cases reported, prompt thoracic duct ligation may be life saving (two of the four reported cases). ${ }^{\text {? }}$

The exact cause of death in this case is not known in view of the lack of necropsy data. According to the literature, mortality in this condition is usually due to malnutrition, lympho- penia, and superimposed infection. ${ }^{7}$ Massive osteolysis was not cited as a possible cause in recent reviews of chylothorax. ${ }^{910}$ Considering the aggressive nature of this complication, physicians should be aware of massive osteolysis as a possible underlying cause of chylothorax.

1 Gorham LW, Wright AW, Schultz HH, Maxon FC Jr. Disappearing bones: a rare form of massive osteolysis. Report of two cases: one with autopsy findings. $A m \mathcal{F} M e d$ 1954;17:674-82.

2 Gorham LW, Stout AP. Massive osteolysis (acute spontaneous absorption of bone, disappearing bone) : its relation to hemangiomatosis. F Bone foint Surg [Am] 1955; 37:985-1004.

3 Halliday DR, Dahlin DC, Pugh DG, Young HH. Massive osteolysis and angiomatosis. Radiology 1964;82:637-44.

4 Takamoto RM, Armstrong RG, Stanford W, Fontenelle LJ, Troxler G. Chylothorax with multiple lymphangiomata of the bone. Chest 1971;59:687-9.

5 Choma ND, Biscotti CV, Bauer TW, Mehta AC, Licata AA. Gorham's syndrome: a case report and review of the literature. Am f Med 1987;83:1151-6.

6 Hardegger F, Simpson LA, Segmueller G. The syndrome of idiopathic osteolysis. $\mathcal{F}$ Bone foint Surg $[\mathrm{Br}]$ 1985;67: 89-93.

7 Tie MLH, Poland GA, Rosenow EC. Chylothorax in Gorham's syndrome: a common complication of a rare disease. Chest 1994;105:208-13.

8 Feigl D, Seidel L, Marmor A. Gorham's disease of the clavicle with bilateral pleural effusions. Chest 1981;79: clavicle

9 Valentine VG, Raffin TA. The management of chylothorax. Chest 1992;102:586-91.

10 Teba L, Dedhia HV, Bowen R, Alexander JC. Chylothorax review. Crit Care Med 1985;13:49-52. 